\section{Michael D Feher,}

Consultant in Diabetes and Clinical Pharmacology, Clinical Lead for Diabetes, Beta Cell Diabetes Centre, Chelsea and Westminster Hospital, London.

\section{REFERENCES}

1. UK Prospective Diabetes Study (UKPDS) Group. Effect of intensive blood-glucose control with metformin on complications in overweight patients with type 2 diabetes (UKPDS 34). Lancet 1998; 352(9131): 854-865.

2. Knowler WC, Barrett-Connor E, Fowler SE, et al. Reduction in the incidence of type 2 diabetes with lifestyle intervention or metformin. N Engl J Med 2002; 346(6): 393-403.

3. National Collaborating Centre for Chronic Conditions. Type 2 diabetes. National clinical guidelines for managmen in primary and secondary care (update). http://www. nice.org.uk/nicemedia/pdf/CG66diabetesfullguideline.pdf (accessed 14 Jul 2008).

4. Nissen SE, Wolski K. Effect of rosiglitazone on the risk of myocardial infarction and death from cardiovascula causes. N Engl J Med 2007; 356(24): 2457-2471.

5. Erdmann E, Dormandy JA, Charbonnel B, et al. The effect of pioglitazone on recurrent myocardial infarction in 2445 patients with type 2 diabetes and previous myocardial infarction: results from the PROactive (PROactive 05)
Study. J Am Coll Cardiol 2007; 49(17): 1772-1780.

6. UK Prospective Diabetes Study (UKPDS) Group. Intensive blood-glucose control with sulphonylureas or insulin compared with conventional treatment and risk of complications in patients with type 2 diabetes (UKPDS 33). Lancet 1998; 352(9131): 837-853.

7. Nauck M, Stöckmann F, Ebert R, Creutzfeldt W. Reduced incretin effect in type 2 (non-insulin-dependent) diabetes. Diabetologia 1986; 29(1): 46-52.

8. Levy JC. Therapeutic intervention in the GLP-1 pathway in type 2 diabetes. Diabet Med 2006; 23(Suppl 1): 14-19.

9. Vilsbøll T, Brock B, Perrild H, et al. Liraglutide, a once-daily human GLP-1 analogue, improves pancreatic B-cell function and arginine-stimulated insulin secretion during hyperglycaemia in patients with type 2 diabetes mellitus. Diabet Med 2008; 25(2): 152-156.

10. Kim D, MacConell L, Zhuang D, et al. Effects of onceweekly dosing of a long-acting release formulation of exenatide on glucose control and body weight in subjects with type 2 diabetes. Diabetes Care 2007; 30(6): 1487-1493.

11. Richter B, Bandeira-Echtler E, Bergerhoff K, Lerch CL. Dipeptidyl peptidase-4 (DPP-4) inhibitors for type 2 diabetes mellitus. Cochrane Database Syst Rev 2008; (2): CD006739.

12. ADVANCE Collaborative Group, Patel A, MacMahon S, Chalmers J, et al. Intensive blood glucose control and vascular outcomes in patients with type 2 diabetes. $N$ Engl J Med 2008; 358(24): 2560-2572.
13. Action to Control Cardiovascular Risk in Diabetes Study Group, Gerstein HC, Miller ME, Byington RP, et al. Effects of intensive glucose lowering in type 2 diabetes. $N$ Engl J Med 2008; 358(24): 2545-2559.

14. Jiang W J. Sirtuins: novel targets for metabolic disease in drug development. Biochem Biophys Res Commun 2008: doi:10.1016/j.bbrc.2008.06.048.

15. Nayagam VM, Wang X, Tan YC, et al. SIRT1 modulating compounds from high-throughput screening as antiinflammatory and insulin-sensitizing agents. J Biomo Screen 2006; 11(8): 959-967.

16. Feher M, Cox A, Munro N. Management of hyperglycaemia in type 2 diabetes: a clinician's algorithm. Br J Diab Vas Dis 2008; 8: 3-4.

DOI: 10.3399/bjgp08X319684

ADDRESS FOR CORRESPONDENCE

\section{Neil Munro}

Beta Cell Diabetes Centre, 2nd Floor, Chelsea \& Westminster Hospital, 396 Fulham Road, SW10 9NH

E-mail: neil.m.munro@btinternet.com

\title{
Reducing the rise in type 2 diabetes
}

The York and Humber Public Health Observatory $^{1}$ reports that $4.7 \%$ of the population now have diabetes, of which $92 \%$ (4.3\% of the population) have type 2 diabetes. The diagnosed prevalence has doubled between 1994 and 2003. The increasing number of people with type 2 diabetes reflects several factors: an ageing population; a true increase in prevalence, related to increased prevalence of overweight and obesity; decreasing physical activity; better survival of those with diabetes due to improved control of blood glucose, blood pressure, and lipids; and earlier diagnosis, partly from informal screening. (A recent study using British general practice data found that one-third of people aged over 40 years [excluding those known to have diabetes] underwent blood glucose measurement in the previous 2 years. ${ }^{2}$ )

The debate on whether there should be organised screening has shifted towards a broad-based approach of cardiovascular risk reduction. This is logical, as the main risk for those with undiagnosed type 2 diabetes is vascular disease. The arguments for screening are that:

- Many people with type 2 diabetes, perhaps $20 \%$ although some estimates are higher, are undiagnosed.

- People can develop complications such as eye disease, before they develop symptoms and have their diabetes diagnosed.

- The risk of heart disease is increased, and the first symptom of heart disease may be a heart attack which is often fatal.

- People with impaired glucose tolerance (IGT) are also at higher risk of heart disease than those with normal glucose levels. ${ }^{3}$

- Progression to diabetes can be reduced or delayed by lifestyle measures (and by drug therapy, such as metformin).

So the aim of screening would be to treat hyperglycaemia and the vascular risk at an early stage, and to prevent complications. ${ }^{4}$

There is then the additional debate about whom to screen. Consensus exists on the need for selective screening, by age and risk factors. For practical purposes (given that screening would be done in primary care), the other factors would be those which are: firstly, recorded in GP records, and secondly, are strongly predictive of diabetes or 'prediabetes'. So screening might be based on: age over 40 years; body mass index (BMI) over $26 \mathrm{~kg} / \mathrm{m}^{2}$; presence of other markers of metabolic disease such as hypertension, high cholesterol or triglycerides, ischaemic heart disease, or peripheral arterial disease; and, if available, family history of diabetes or other metabolic disease. In reality, age and BMI provide a good basis for selection. ${ }^{5}$

If we did have organised screening, we would, depending on the test used and the cut-offs chosen, detect more people with lesser degrees of glucose impairment, such as IGT, than with undiagnosed diabetes. Macrae and colleagues ${ }^{6}$ screened high-risk patients and found $8.5 \%$ to have type 2 diabetes, and $9.6 \%$ to have IGT or impaired fasting glycaemia. In the wider population, there are probably about three times as many people with IGT as with type 2 diabetes. Non-pharmacological interventions with diet and physical activity have been shown to be effective in large trials in Finland, the US, India, and China. But these trials involved volunteers in whom compliance is likely to be much better than average, and even in them compliance waned over time, despite continued intervention. In other studies, once the intervention stopped, the effect was soon lost.

The duration of many trials is far too short 
to show whether lifestyle changes and the benefits were sustained. We know that lifestyle change is often not maintained. In this issue of the journal, Colin Greaves et a/ ${ }^{p}$ report that a pilot study showed promising results at 6 months. Many such studies do, but in most cases the benefit does not persist after the intervention ceases. If they go on to a full trial, Greaves and colleagues should have follow-up for at least 3 years post-intervention.

Similarly, the ISAIAH results ${ }^{8}$ are only to 6 months, but again, that was a feasibility study and a full trial could be much longer. Also in this issue results from the Counterweight Programme are reported, ${ }^{9}$ but the impact of those is reduced by the lack of controls and the high drop-out rate.

The best results were in the Finnish Diabetes Prevention Study. A 58\% reduction in progression to diabetes was reported at 3 years. ${ }^{10}$ Over time the reduction fell, but at 7 years, there was still a $43 \%$ reduction compared to the control group, 3 years after the 4-year intervention period ended. ${ }^{11}$ In absolute terms, by the sixth year, $38 \%$ of the control group and $23 \%$ of the intervention group had developed diabetes. The intervention was quite intensive. The lifestyle group had frequent face-to-face meetings with a nutritionist, individualised advice (both verbal and written), exercise programmes (including twice weekly supervised circuit training), and assessment of compliance by regular interviews at clinic follow-up.

GPs might well think that rather than spend a lot of time on often fruitless efforts at promoting lifestyle change, that it would be more cost-effective just to start metformin and a statin: both cheap, safe, and effective. That is perhaps too pessimistic, and it is worth giving people a chance on diet and physical activity, especially given the long-term benefit of physical activity. ${ }^{11}$ (I use the term 'physical activity' rather than 'exercise' because it is likely that most patients with newly diagnosed diabetes won't start going to gyms or jogging. Some will, but there is a greater chance of them finding walking or cycling more acceptable.) But most will end up on drug treatment, and since we know that type 2 diabetes is usually a progressive disease, they will graduate to treatment with more than one oral glucose-lowering drug, and many will end up on insulin.
I think a key question for governments in addressing the rise in type 2 diabetes and its precursors, is the balance between the 'medical model' (screening and health care interventions) and public health measures. This was raised in a survey of GPs and practice nurses' views by Rhys Williams and colleagues. ${ }^{12}$ One practice nurse responded that asking primary care staff to take on the identification and management of patients with IGT and impaired fasting glucose 'almost medicalises something which is actually a social problem'.

In theory, we could prevent most cases of type 2 diabetes if we could persuade the population to be more active and keep to an ideal weight. We don't seem to be succeeding at present.

A key issue for the government is how to deal with unhealthy lifestyles: whether to assume failure and apply medical measures, such as screening and drug treatment, or seek to combat the rising prevalences of obesity and diabetes by government action. Health education does not seem to work, so perhaps tougher measures are needed, along with evaluation of current methods. There could be many options for government, but some would be unpopular with the electors, and are unlikely to be adopted by politicians. Government actions could include:

- Being much tougher on food manufacturers: a tax on the saturated fat, salt and sugar contents of food.

- Encouraging physical activity: cycle lanes completely separate from other road traffic would be a good start. Better lighting and other ways of making streets safer to walk in might also help.

- Increasing the tax on alcoholic drinks: the greatest harm done by alcoholic drinks may be from calories rather than alcohol.

- Encouraging personal responsibility for health by financial incentives or disincentives: perhaps people with high BMls should pay for prescriptions for diabetes drugs and statins.

- Encouraging government employees, especially those in direct contact with patients, to take responsibility for their health so that they set good examples.

It would be difficult for any government to propose such strategies, and most would be unlikely to gain widespread support. There is a tension between people's right to choose their own lifestyles, and the impact that those lifestyles have on NHS costs, and hence the opportunity costs to other people who will be deprived of some other form of health care. But in the absence of an effective public health strategy, the prevalences of obesity and diabetes will rise further, with inevitable consequences in terms of morbidity, mortality, workload, and costs.

\section{Norman Waugh,}

Department of Public Health, University of Aberdeen.

\section{REFERENCES}

1. Yorkshire and Humber Public Health Observatory. Diabetes. http://www.yhpho.org.uk/diabetes.aspx (accessed 8 Jul 2008).

2. Holt TA, Stables D, Hippisley-Cox J, et al. Identifying undiagnosed diabetes: cross sectional survey of 3.6 million patients' electronic records. Br J Gen Pract 2008; 58(548): 192-196.

3. The DECODE Study Group of the European Diabetes Epidemiology Group. Glucose tolerance and mortality: comparison of WHO and American Diabetes Association diagnostic criteria. Lancet 1999; 354(9179): 617-621.

4. Waugh N, Scotland G, McNamee P, et al. Screening for type 2 diabetes: literature review and economic modelling. Health Technol Assess 2007; 11(17): iii-iv, ix-xi, 1-125.

5. Greaves CJ, Stead JW, Hattersley AT, et al. A simple pragmatic system for detecting new cases of type 2 diabetes and impaired fasting glycaemia in primary care. Fam Pract 2004; 21(1): 57-62.

6. Macrae MJ. Screening for type 2 diabetes. BrJ Gen Pract 2004; 54(507): 785.

7. Greaves CJ, Middlebrooke A, O'Loughlin L, et al. Motivational interviewing for modifying diabetes risk: a randomised controlled trial. Br J Gen Pract 2008; 58(553): 535-540.

8. Barclay C, Procter KL, Glendenning R, et al. Can type 2 diabetes be prevented in UK general practice? A lifestyle change feasibility study (ISAIAH). Br J Gen Pract 2008; 58(553): 541-547.

9. Counterweight Project Team. Evaluation of the Counterweight Programme for obesity management in primary care: a starting point for continuous improvement. Br J Gen Pract 2008; 58(553): 548-554.

10. Tuomilehto J, Lindström J, Eriksson JG, et al. Prevention of type 2 diabetes mellitus by changes in lifestyle among subjects with impaired glucose tolerance. N Eng J Med 2001; 344(18): 1343-1350.

11. Lindström J, Ilanne-Parikka P, Peltonen M, et al. Sustained reduction in the incidence of type 2 diabetes by lifestyle intervention: follow-up of the Finnish Diabetes Prevention Study. Lancet 2006; 368(9548): 1673-1679.

12. Williams R, Rapport F, Elwyn G, et al. The prevention of type 2 diabetes: general practitioner and practice nurse opinions. Br J Gen Pract 2004; 54(504): 531-535.

DOI: 10.3399/bjgp08X319693

\section{ADDRESS FOR CORRESPONDENCE}

Norman Waugh

Department of Public Health,

Medical School Buildings, Foresterhill,

Aberdeen AB25 2ZD

E-mail: N.R.Waugh@abdn.ac.uk 